\section{Durkheim, o individualismo e os intelectuais}

\section{Durkheim, individualism and intellectuals}

DURKHEIM, Émile; organização e edição Marcia Consolim, Márcio de Oliveira, Raquel Weiss. Edição Bilíngue e Crítica. O Individualismo e os Intelectuais. São Paulo: Editora da Universidade de São Paulo, 2016, vol. 1, 192p.

\section{Jayme Gomes Neto}

Doutorando em Sociologia pela Universidade Federal do Rio Grande do Sul (UFRGS), Porto Alegre - RS, Brasil. E-mail: jaymegomesnt@gmail.com

DOI: $10.1590 / 339818 / 2018$

Encabeçada por uma nova geração de competentes pesquisadores brasileiros, a coleção Biblioteca Durkheimiana, iniciada em 2016, pela editora da Universidade de Sáo Paulo (Edusp), tem trazido ao público textos esgotados ou inéditos da chamada "escola durkheimiana". Além das versóes bilíngues, no que as cuidadosas traduçóes podem ser sempre comparadas e cotejadas com a versão original do texto, as edições trazem sempre um "dossiê crítico" com artigos feitos por especialistas e, por fim, "anexos", tais como cartas, fotos, resenhas e outros documentos históricos. Nessa bem sucedida mescla entre texto, contexto e aparato crítico, o leitor encontra não somente as condiçôes de uma apreciação detalhada do texto e sua época, mas a possibilidade de alçar voos maiores.

$\mathrm{O}$ volume de estreia da coleção, organizado por Marcia Consolim, Marcio de Oliveira e Raquel Weiss traz o texto "O individualismo e os intelectuais”, de Émile Durkheim. Além de uma introdução histórica feita pelos organizadores, a edição conta ainda com considerável material complementar. $\mathrm{Na}$ seção "dossiê crítico", encontramos análises feitas por Louis Pinto, Marcia Consolim, Susan Stedman Jones, Raquel Weiss e William Watts-Miller, alguns dos principais especialistas brasileiros e internacionais no que diz respeito à obra e ao legado durkheimianos. Por fim, na seção "anexos", encontramos alguns documentos históricos bastante inte- ressantes, tais como fotos e textos da mesma época compondo um diálogo com "O individualismo e os intelectuais".

Publicado em 1898 pela La Revue politique et littéraire (também conhecida como Revue Bleue) o texto constitui um testemunho do engajamento ético de Durkheim em relação a uma série de valores que pareciam sob ataque naquele momento e que dividiram a França da Terceira República, por ocasião do episódio conhecido como "caso Dreyfus". Apesar do impacto de sua publicação - no que vale mencionar a reação negativa de alguns colegas de Durkheim e certo isolamento enfrentado pelo sociólogo, em Bordeaux -, o texto acabou por ser esquecido nas décadas seguintes, sendo "redescoberto" por especialistas somente no fim dos anos 1960. Graças a esse movimento - e à atuação de nomes importantes, tais como Steven Lukes (1969), Jean Claude Filloux (1975) e Robert Bellah (1973), que contribuíram para a sua divulgação - o texto passou a ser reconhecido, a partir de então, como peça importante dos estudos durkheimianos e ocupa hoje uma posição bastante singular no interior de sua obra.

Como bem aponta a minuciosa introdução dos organizadores, a escrita de "O individualismo e os intelectuais" remonta ao episódio de 1894, no qual o oficial do exército francês, Alfred Dreyfus, de origem judia, foi acusado de ter entregue segredos de estado em um bilhete interceptado a caminho da embaixada alemã. Mesmo com exames grafológicos inconclusivos e sem maiores evidências, o oficial foi condenado à prisão e transferido para a Guiana Francesa. Nos anos seguintes, entretanto, novas evidências foram encontradas e ficou provado que a letra do bilhete pertencia, na verdade, a outro oficial do exército. Em um contexto de crescente antissemitismo na sociedade francesa, ficava cada vez mais claro que se tratava de uma perseguição contra Dreyfus, mas o exército negava-se a rever sua posição.

A divisão que até então se gestava no interior da sociedade francesa, a respeito do acontecido, acabou por ganhar contornos mais claros após a intervençáo do escritor Émile Zola. Em seu famoso artigo endereçado ao presidente da república, que ficaria conhecido como "J'accuse" (Eu acuso), o escritor defendia Dreyfus e denunciava sua perseguição. Eis as 
condiçóes gerais da polêmica que passou a dividir a sociedade francesa: de um lado, encontravam-se os chamados dreyfusards, em sua maior parte constituída por republicanos e aqueles pertencentes a setores mais progressistas da vida social francesa, que defendiam a revisão do processo em nome dos direitos individuais; de outro, encontravam-se os antidreyfusards, em sua maioria composta por monarquistas, católicos e setores mais conservadores da sociedade francesa, que acreditavam na culpa de Dreyfus ou, ao menos, defendiam a manutenção da decisão do exército em nome da "razóes de estado".

É em meio a essa polêmica que se insere o texto de Durkheim. Mais especificamente, trata-se de uma intervenção pública em que ele responde ao conhecido artigo de Ferdinand Brunetière, "Après le procès" (após o processo), no qual os chamados "intelectuais" (associados aos dreyfusards) eram acusados de "individualismo". Tratava-se, nas palavras de Brunetière, da grande doença do tempo atual, postura nociva às instituiçóes, à democracia e, sobretudo, à nação francesa (Brunetière, 2016, p.163). Durkheim, que fora signatário do Manifesto dos Intelectuais - documento em torno do qual se reuniram milhares de escritores, artistas, filósofos e cientistas - e também secretário da Liga dos Direitos do Homem, em Bordeaux, responde, em nome dos "intelectuais", defendendo o caráter inviolável da pessoa e o universalismo dos direitos humanos. Mas, antes de adentrar o texto durkheimiano em maiores detalhes, cabem ao menos duas consideraçôes mais gerais sobre ele.

A primeira consideração é a de que sua leitura nos informa, de maneira privilegiada, quais tipos de compromissos éticos e políticos moviam o autor. Muitas vezes lido como uma espécie de conservador, Durkheim aparece aqui engajado com os setores mais progressistas da sociedade francesa de sua época, advogando em defesa de um humanismo universalista que visa aprofundar os lemas da revolução de 1789 . Trata-se, nas palavras do autor, de uma posição marcada pela “(...) simpatia por tudo o que é humano, uma maior piedade por todas as dores e por todas as misérias humanas, bem como uma necessidade ardente de combatê-las e de atenuá-las, e, enfim, uma maior sede de justiça" (Durkheim, 2016, p. 49).
Uma segunda consideração diz respeito ao fato de que, do ponto de vista da teoria sociológica e do diagnóstico da modernidade durkheimianos, o texto em questáo fornece um ponto de ligaçáo entre o jovem Durkheim de A Divisáo do Trabalho Social (1893) e o Durkheim maduro de As Formas Elementares da Vida Religiosa (1912). ${ }^{1}$ Vemos, nesse caso, como o autor mantinha a preocupação de seu primeiro grande livro a respeito da crise das sociedades ocidentais, nas quais a crescente especialização das funçôes sociais, decorrente da divisão do trabalho, era a todo momento marcada pela ameaça da desintegração valorativa e pela perda de referencial normativo das açóes dos indivíduos. Em "O individualismo e os intelectuais", Durkheim argumenta que a pessoa humana, alçada à posição de um sagrado moderno, seria a única figura dotada de força normativa capaz de fundar uma verdadeira solidariedade nas sociedades industriais e a única capaz de remeter, nesse contexto, a uma generalizada efervescência dos afetos. Ora, ao insistir no fenômeno do sagrado (embora, nesse caso, um sagrado laico) como fundamento da vida social, assim como em sua dimensão efervescente, vemos como Durkheim também antecipa algumas das questôes presentes em As Formas Elementares.

\section{"O Individualismo e os Intelectuais"}

Em sua resposta ao texto de Brunetière, Durkheim se abstém de comentar os meandros do caso e seus acontecimentos particulares, mantendo o foco primordial nos princípios em disputa na sociedade francesa. Em especial, trata-se de responder à acusação de que os "intelectuais", ao defenderem os direitos de Dreyfus e denunciarem as condenações dos tribunais militares, colocariam o egoísmo e o particularismo individuais acima daquela que era concebida por muitos como a instituição central da nação francesa, o exército. Parte da estratégia central de Durkheim consiste em esclarecer os termos do debate em torno do legado liberal, no que o sociólogo empreende a defesa de um tipo específico de individualismo por meio de argumentos a um só tempo filosóficos (partes I e II), sociológicos (parte III) e histórico-prospectivos (parte IV). 
$\mathrm{Na}$ primeira parte do texto, Durkheim trata de promover um esclarecimento conceitual em relação ao termo "individualismo". Aos olhos do sociólogo, haveriam duas linhagens do individualismo que deveriam ser distinguidas. A primeira delas remeteria ao individualismo "egoísta", representado de maneira mais bem acabada pelo utilitarismo de Herbert Spencer. Essa linhagem de pensamento, que não concebe a existência - ou, ao menos, o direito à existência - de fins que não aqueles estritamente individuais, linhagem de pensamento para a qual a sociedade não seria mais do que "um vasto aparelho de produção e de troca", não passaria, na verdade, de um "mercantilismo mesquinho" e seria, aos olhos do sociólogo, dotada de uma "miséria moral" incompatível com a vida social: ““(...) pois está bastante claro que toda a vida comum seria impossível se não existissem interesses superiores aos interesses individuais" (Durkheim, 2016, p.41).

A essa concepção de individualismo, marcada por uma espécie de liberdade negativa, Durkheim contrapóe um individualismo universalista - cujo ideal de "liberdade" seria o da autonomia - que remontaria às figuras de Kant, Rousseau, os Espiritualistas $^{2}$ e a toda a tradição da Declaração dos Direitos do Homem. Em todos estes casos, o fundamento da ação moral não poderia ser dado, em última instância, pela figura daquilo que é particular, hipotético e contingente. Pelo contrário, diz Durkheim, trata-se de insistir que aquilo que recai sob o signo do dever e do bem é, antes, algo que ultrapassa a individualidade imediata, a fim de alcançar o que convém à humanidade indistintamente, isto é, aquilo que convém ao homem em geral. $\mathrm{O}$ arremate vem em seguida e já aponta para aquilo que será, mais tarde, uma linha geral do argumento durkheimiano: somente o próprio homem pode aparecer como parâmetro último do dever nas sociedades modernas.

Esse ideal ultrapassa de tal maneira o nível dos fins utilitários, que ele aparece às consciências que o aspiram como impregnado de religiosidade. A pessoa humana, cuja definição é como a pedra de toque por meio da qual o bem se distingue do mal, é considerada sagrada por assim dizer, no sentido ritual do termo. (...) Tal moral não é simplesmente uma disciplina higiênica ou uma sensata economia da existência, mas uma religiáo em que o homem é, ao mesmo tempo, o fiel e o Deus (Durkheim, 2016, p. 43-5).

$\mathrm{Na}$ segunda parte do texto, Durkheim aprofunda a definição conceitual pré-estabelecida a fim de investigar, ainda do ponto de vista filosófico, qual seu verdadeiro fundamento normativo. $\mathrm{O}$ que pressupóe, afinal de contas, uma visão moral de mundo que exige como critério do que pode ser alçado à posição de bem justamente aquilo que não se confunde com a particularidade do empírico e com a singularidade dos afetos? Trata-se, é claro, de uma concepção na qual a ação e a moralidade são submetidas a critérios de racionalidade gerais e intersubjetivamente acessíveis, donde emana, precisamente, suas alegadas pretensóes de justiça e equidade. Tendo como pano de fundo um racionalismo desse tipo é que Durkheim pode afirmar, numa verve kantiana, que "esse culto do homem [compreendido como símbolo da humanidade da qual participa] tem como primeiro dogma a autonomia da razão e como primeiro rito o livre exame" (Durkheim, 2016, p.49).

Ao insistir nesse tipo de encaminhamento, o sociólogo procura responder à crítica daqueles que equacionam o individualismo dos "intelectuais" à anarquia social. Pois argumentar em nome da autonomia de pensamento, para o autor, não significa sucumbir a um relativismo de opiniōes no qual a "liberdade" seria apenas um outro nome dado à sua não comunicação e à sua falta de coordenação anárquica. Na perspectiva de Durkheim, a liberdade e a autonomia não seriam incompatíveis com a ordenação social e com a autoridade institucional. O que não se admite, entretanto, diz ele, é que se dêem ao luxo da arbitrariedade e da não fundamentação, pois a autoridade social sempre demanda, nesse novo momento histórico, a argumentação e o convencimento racionais. "Tudo que é necessário são apenas razões para que minha razão se incline diante da de outro. $\mathrm{O}$ respeito pela autoridade nada tem de incompatível com esse racionalismo desde que a autoridade esteja racionalmente fundamentada” (Durkheim, 2016, p. 51). Eis as condiçóes de possibilidade da ordenaçáo dessa nova forma de 
vida social que encontra na pessoa humana o seu valor mais sagrado.

$\mathrm{Na}$ terceira parte do texto, as definiçóes conceituais e os argumentos filosóficos dão lugar a uma reflexão que faz o inquérito do individualismo em termos de sua fundamentação propriamente sociológica. Nesse momento, Durkheim retoma um argumento que já havia sido mobilizado em seu primeiro grande trabalho, $A$ Divisão do Trabalho Social, e que voltaria a aparecer ao longo de sua obra: trata-se da identificação de um processo histórico de complexificação social que seria marcado, no campo material, pela divisão do trabalho e pela autonomização das funçóes sociais e, no campo representacional (intelectual e moral), por um processo de racionalização. ${ }^{3}$ Pois em um ambiente de adensamento das relaçóes sociais, crescimento populacional e expansão territorial, os diferentes contextos situacionais exigiriam como requisito comunicacional que as representaçóes da consciência fossem capazes de operar de maneira cada vez mais abstrata. Nesse movimento, "caminha-se pouco a pouco em direção a um estado (...) no qual os membros de um grupo social não terão mais nada em comum entre si senão sua qualidade de homens e os atributos da pessoa humana em geral" (Durkheim, 2016, p. 55). Eis como um processo sociológico - de crescimento e complexificação social - nos leva a uma racionalização prática na qual sobrevém a representação coletiva da pessoa humana como o ponto mais alto de abstração e, por isso mesmo, a única capaz de atender os critérios de uma religião das sociedades modernas.

Tal religião, no entanto, não constituiria uma ruptura completa com o passado. Durkheim nos lembra como, por exemplo, o desenvolvimento do individualismo moral constituía um elemento fundamental do cristianismo: "Ele [o cristianismo] foi o primeiro a ensinar que o valor moral dos atos deve ser medido pela intenção, coisa íntima por excelência (...)" (Durkheim, 2016, p. 57). A religião da humanidade não constituiria senão o aprofundamento desse processo social de larga escala no qual "o centro da vida moral [é] (...) transportado do exterior para o interior" (Durkheim, 2016, p. 57). Ora, ao insistir no caráter religioso do individualismo moderno, Durkheim também justifica, de um ponto de vista sociológico, a indignação e a reação dos "intelectuais" por ocasião do "caso Dreyfus". Pois violar os direitos da pessoa humana equivaleria, nesse caso, a violar o único valor capaz de ligar todas as consciências numa espécie de comunhão moral. Uma tal profanação do sagrado moderno, dizia o sociólogo, náo poderia deixar de colocar em risco a própria sociedade.

$\mathrm{Na}$ quarta e última parte do texto, Durkheim faz apelo à memória de acontecimentos franceses recentes - em especial, o clima de abatimento que se sucedeu às lutas por liberdades políticas na Terceira República francesa -, a fim de expor uma visão prospectiva a respeito do fenômeno do individualismo. Para o sociólogo, é claro que o individualismo do século XVIII, embora imprescindível, seria insuficiente em fins do século XIX. Parte da experiência histórica francesa testemunharia a necessidade de um individualismo capaz de ultrapassar um critério de liberdade negativa. Pois, de fato, a liberdade de votar, de escrever, de pensar e quaisquer outras que apontem para a ausência de constriçốes à expressão humana não poderiam ser senão meios para um fim com o qual não se confundem. Colocar a questão nestes termos é o modo durkheimiano de insistir em uma tarefa histórica determinada: "trata-se de completar, de ampliar, de organizar o individualismo (...)" (Durkheim, 2016, p. 63).

Mas o que significa esse movimento de ampliação? Em termos teóricos, isso significa substituir a ideia negativa de liberdade pela ideia positiva de autonomia do homem. Em termos mais práticos, isso significa não apenas a retirada de barreiras, mas o fornecimento de condiçóes positivas de realização desse mesmo homem: "utilizemos, portanto, nossas liberdades para (...) amenizar o funcionamento da máquina social ainda tão rude aos indivíduos; para pôr ao seu alcance todos os meios possíveis de desenvolver suas faculdades sem obstáculos" (Durkheim, 2016, p. 63). Trata-se de encontrar "os meios de organizar a vida econômica e de introduzir uma maior justiça nas relaçóes contratuais!" (Durkheim, 2016, p.63). Ora, a preocupação com as crises econômicas e com a promoção de uma maior justiça social nas relaçóes contratuais, como se sabe, era uma das preocupaçóes fundamentais de Durkheim nesse período. Isso fica claro em seu cur- 
so sobre o Socialismo, ministrado dois anos antes, e no longo prefácio que escreverá para a segunda edição da Divisão do Trabalho Social, quatro anos depois. A leitura desses textos, aliás, nos ajuda a compreender a perspectiva do sociólogo: segundo ele, a soluçáo de tais problemas dependeria, ao menos em parte, da capacidade das sociedades democráticas modernas quanto à criação de canais de comunicação de poder e à promoção de um fortalecimento (material e simbólico) de grupos sociais intermediários, no que os agrupamentos profissionais teriam um papel destacado. Eis o ponto para o qual parece convergir sua defesa ética apresentada no ensaio de 1898.

\section{Dossiê Crítico}

Na seção do "dossiê crítico" encontram-se cinco artigos - aos quais dedicaremos algumas palavras nos próximos parágrafos - que auxiliam o leitor na realização de seu percurso, seja por meio de uma contextualização mais detalhada da polêmica, seja por meio de uma reconstrução mais aprofundada dos argumentos do texto e suas relaçóes com outros textos, ou ainda, por meio de tentativas de reatualização e releitura dos argumentos em jogo.

No artigo, "O Intelectual como Mandatário do Universal", Louis Pinto prossegue na tentativa de explicitar as condiçóes sociais de emergência do campo intelectual francês de fins do século XIX, com suas respectivas disputas e tomadas de posição. Nesse embate entre dreyfusards e antidreyfusards, Pinto mostra que mais do que uma simples oposição político-ideológica entre conservadores e progressistas, o que estava em jogo, no meio intelectual, era uma disputa a partir da qual se contrapunham, de um lado, as disciplinas "clássicas" e literárias e, de outro, as disciplinas "modernas" e científicas. Em meio a essa polarização, o que se colocava em pauta era o próprio papel da ciência e de seus porta-vozes no interior da vida social francesa. Nesse contexto, Pinto mostra como Durkheim se aliava ao campo daqueles que acreditavam no papel público do intelectual, cujo saber e o discernimento se colocariam em nome de um uso autônomo e crítico da razão, verdadeira fonte de legitimidade nas sociedades democráticas. Para o autor, o intelectual durkheimiano apareceria assim como uma espécie de "mandatário do universal"

No artigo de Márcia Consolim, "O Século das Grandes Revistas Parisienses: Revue de deux mondes e a Revue bleue antes do Affaire", fica claro que a compreensão textual não pode ser desligada do meio de sua publicação. Em uma descrição histórica detalhada dos diferentes projetos editoriais em jogo, a autora nos mostra como as revistas parisienses compunham um espaço altamente hierarquizado e diferenciado. Nesse caso, a produçáo intelectual aparece como um processo complexo que só pode ser devidamente descrito e analisado fazendo referência aos diretores destas publicaçóes, assim como às relaçóes estabelecidas entre as revistas, determinados setores da universidade e público leitor. As revistas, nesse contexto, compunham espaços estratégicos para a disseminação de certos projetos intelectuais, possibilitando o aparecimento de redes e grupos de sociabilidade.

Em "O Individualismo", terceiro artigo do dossiê, Susan Stedman Jones empreende uma reconstruçáo do individualismo de Durkheim em três dimensões: filosófica, socio-histórica e política. Do ponto de vista filosófico, a autora mostra como o holismo durkheimiano não seria incompatível com a figura do indivíduo, tomando-a, antes, como peça fundamental da explicação sociológica. Pois racionalismo filosófico - na esteira de Leibniz, Kant e, principalmente, Renouvier - encontraria na noção de "personalidade individual", isto é, aquilo que singulariza um exemplar, um elemento fundamental da representação do ser e, portanto, parte essencial de sua epistemologia. A isso se ligaria então a dimensáo socio-histórica do argumento: esse elemento central à lógica da representação, a "personalidade" do ser, ganharia um relevo particular na história das sociedades ocidentais justamente em decorrência de um processo de complexificação social e de divisão do trabalho. $\mathrm{O}$ aparecimento da personalidade seria, segundo Jones, como que o resultado lógico da autonomização (relativa) do ser individual frente ao ser social (que também se torna uma espécie de personalidade de segunda ordem). ${ }^{4}$ Mas a autonomia remeteria também a uma dimensão normativa cujo referencial último seria 
dado por uma figura da liberdade da vontade. Eis o modo como as dimensóes filosóficas e socio-históricas do pensamento durkheimiano se concatenam com a dimensäo política de um individualismo centrado na defesa do livre pensamento, nos direitos fundamentais da pessoa humana e na busca pelas condiçôes (materiais e simbólicas) de sua realização.

O quarto artigo, "Durkheim, um 'Intelectual' em Defesa do 'Ideal Humano", é de autoria de Raquel Weiss. Nele a autora defende o texto como peça importante de uma compreensão renovada da figura do sociólogo, para além da caricatura clássica que o tomaria como uma espécie de teórico conservador. Mais do que isso, o texto contribuiria à compreensão de aspectos que não ficam evidentes nos trabalhos mais canônicos do autor. Pois, nesse caso, a abordagem positiva dos fenômenos sociais seria complementada pela defesa normativa de um ideal. Para Weiss, trata-se da defesa do ideal kantiano do "reino dos fins" - que toma como ideal ético a ação autônoma e como ideal político uma sociedade de sujeitos que são fins da ação, e não meios - mediante uma justificação sociológica dupla: por um lado, sua gênese seria compreendida não mais em referência a uma razáo prática pura, mas em meio a uma racionalidade eminentemente intersubjetiva; por outro, sua desejabilidade estaria necessariamente vinculada a um processo social de consagração, o que nos remeteria a determinados episódios de efervescência coletiva. Eis o modo como o texto seria capaz de reconfigurar não só nossa compreensão sobre a figura de Durkheim, mas nossa percepção geral de sua obra.

No último artigo, "'O Individualismo e os Intelectuais' de Durkheim”, William Watts-Miller defende que se leia o ensaio durkheimiano como um ponto privilegiado de articulaçáo entre a obra de juventude e a obra de maturidade do autor. Nesse caso, as primeiras preocupaçôes éticas de Durkheim com relação ao estabelecimento de um ideal igualitário e de uma "sociedade de pessoas" são articuladas com uma abordagem que antecipa a intuição do fundamento religioso da vida coletiva. Watts-Miller mostra o modo pelo qual o individualismo defendido por Durkheim apresenta um caráter transcendente que o distingue do individualismo "sórdido" do utilitarismo na justa medida em que admite um sa- grado inegociável, isto é, que não se submete ao cálculo profano de utilidade. Em sua defesa, fica clara a preocupação do sociólogo francês com certo mal- estar de época, temática que teria perpassado, aliás, toda a sua obra. Por fim, o autor faz um movimento de atualização no qual as preocupaçóes originais de Durkheim sobre a crise de seu tempo aparecem como motor de uma crítica que se direciona também aos atuais adversários éticos do igualitarismo e de uma "sociedade de pessoas", no que o autor destaca as recentes ideologias "neoliberais".

Além dos cinco textos contidos na seçấo "dossiê crítico", o volume traz alguns materiais complementares em anexo. O destaque neste ponto é o próprio texto de Brunetière, cuja inclusão no volume enriquece a experiência do leitor e o coloca em contato direto com o principal interlocutor e adversário de Durkheim durante o ensaio. Levando em conta os seus vários aspectos, é preciso dizer, enfim, que o primeiro volume da Biblioteca Durkheimiana fornece ao leitor tudo o que se espera de uma edição crítica de qualidade, servindo de exemplo a outras publicaçôes e elevando o padrão de expectativa em relação aos volumes subsequentes da mesma coleção.

\section{Notas}

1 A argumentação a respeito da conexão entre o Durkheim jovem e o maduro é melhor desenvolvida na seção do "dossiê crítico", no texto de William Watts-Miller intitulado " $O$ Individualismo e os Intelectuais' de Durkheim".

2 Trata-se da tradição do chamado Espiritualismo Eclético, corrente de pensamento dominante na França, do século XIX, a qual remontaria a nomes como Maine de Biran, Victor Cousin e, posteriormente, Paul Janet. Para mais informaçóes, ver: Schmaus, 2004.

3 Essa teoria da racionalização histórica - que encontra um paralelo inacreditavelmente pouco explorado em relação à teoria weberiana - perpassa, na verdade, os vários momentos da obra durkheimiana, aparecendo em seus principais textos: A Divisäo do Trabalho Social, sua tese de doutorado publicada em 1893; A Educação Moral, curso ministrado entre os anos 1902 e 1903; e, por fim, As Formas Elementares da Vida Religiosa, seu último grande trabalho, publicado em 1912. 
4 Jones afirma, de maneira ousada, que segundo Durkheim esse processo náo seria apenas social, mas também universal. (Jones, 2016, p.88, nota 23).

\section{BIBLIOGRAFIA}

BELLAH, Robert N. (Org.). (1973), Emile Durkheim: On Morality and Society. Chicago and London, The University of Chicago Press.

FILLOUX, Jean-Claude. (1975 [1970]), "Introdução”, in: DURKHEIM, Émile. A ciência social e a acção. São Paulo, Difel.

JONES, Susan Stedman. (2016), "Individualismo", in: DURKHEIM, Émile; M. Consolim, M. de Oliveira \& R. Weiss (orgs.), Edição Bilíngue e Crítica, $O$ Individualismo e os Intelectuais, São Paulo, Editora da Universidade de São Paulo, vol. 1, 2016: 85-94.

LUKES, Steven. (1969), “Durkheim's Individualism and Intellectuals". Political Studies, 1969, n. 18: 14-19.

LUKES, Steven. (1985 [1973]), Emile Durkheim: His Life and Work: a Historical and Critical Study. Stanford, California, Stanford University Press.

SCHMAUS, Warren. (2004), Rethinking Durkheim and his tradition. New York, Cambridge University Press. 